\title{
AN ANALYZING EROSION WEAR ON BLADE OF TURBINE
}

\section{PRAGYAN SENAPATI", SWETA RANI BISWAL \& SOUGAT MAJI}

ITER, Siksha 'O'Anusandhan Deemed to be University, Bhubaneswar, India

\begin{abstract}
This paper discusses the strategy for degradation of surface of hydro turbine edge section brought about by the impact of unpleasant standard particles passed on spilling water is a troublesome issue of disintegration wear. To neutralize the same, surface alteration of turbine edge material by use of defensive covering is getting commonness now days. WC based hard metals are generally utilized in the industry for the most part are being created for a wide variety of employments to contradict wear. Slurry crumbling burdens are especially fundamental in the midst of blustery periods in the hydro control plant. The erosive wear impediment of $86 \mathrm{WC}-10 \mathrm{CO}-4 \mathrm{cr}$ cermet's is upgraded by the extension of $2 \%$ wt. \% of littler scale estimated yttrium oxide, which fills in hard stage. These cermet's covering were put away on 13cr-4Ni martensitic treated steel substrates through fast oxygen fuel method to get an ordinary thickness.

KEYWORDS: HVOF, Coating, Wear \& Stainless Steel
\end{abstract}

Received: Apr 17, 2019; Accepted: May 07, 2019; Published: Jun 12, 2019; Paper Id.: IJMPERDJUN2019167

\section{INTRODUCTION}

Erosive wear of hydro turbine cutting edge sections by dregs particles is a vital issue. The most normally used hydro turbine bleeding edge steel, martensitic solidified steel has a low hardness and get easily deteriorated by the hard particles present in the discharge. High gathering of such lingering particles can result in mutilated sprinter profiles, inefficient yield, disillusionment, and extend bolster cost. A Counter strategy is connected to this issue hard guarded covering superficially at risk to be impacted by wear. Assorted sorts of covering and surface medicine investigated by experts[1].

In weight driven power plant hard particles are passed on by gushing of water , impact the turbine sharp edge fragment at a quick and break down the surface, which prompts genuine mischief of these section. This issue turns out progressively extraordinary in the midst of rainstorm season for hydropower plant organized in Himalayas and it as often as possible prompts shutdown of these plants[2]. Along these line, this issue of slurry crumbling of the surface has pulled in the thought of researcher around the globe. Nevertheless, the examination of slurry breaking down wonder of turbine materials under genuine working conditions is an extraordinarily inconvenience the equivalent under the parts. As such the slurry breaking down test are routinely driven using extraordinarily illustrated deterioration test rig, in which genuine working condition are reenacted. From the exploratory examination it pre-accepted that wear of the target surface depends on various factor microstructure, hardness, shortcoming quality yield and outrageous quality, of the cutting edge material and hardness shape, size of the erodent particles[3,4].

The increment in the disintegration rate with speed is connected with the development in engine imperativeness of the erodent causing more power full mischief on the metal surface. Also, target material properties have been seen as an indispensable parameter that incredibly impacts disintegration that disintegration 
restriction increases with reducing the hardness of the steel. They react that it was the malleability, rather than the hardness, which oversees the crumbling rate. So to keep these disintegration of the turbine sharp edge there are a few covering strategy are utilized[5].

\section{MATERIAL AND METHOD}

\section{Erosion Mechanism}

From the melancholy phases of a toaster that is compressing, steam extends under the line. Wet will get precipitated inside the form of drops. It's always interesting to permit of a level of illness as prospective to advocate a great deal of function out of steam pressure over the vapor offers increase to declines which AR disagreeable. There's a limitation of illness in steam. The prejudices consequences thanks into this existence of water drops at vapor AR --(inch.) Decline of effectiveness of plain water as a result of haul drops at elevated rates. Erosion of blades of plain water because of impingement falls at elevated rates.

Because it not decreases the life of the effectiveness of this point but is elevating, erosion will be a whole good deal of prejudices. [6] Water drops talent inside the steam strike on the blades using comparative speed imposing impression erosion of blades. This erosion horribly lis exceptionally |is remarkably intense and contains a really prejudices impression over the point effectiveness. It truly is essentially recognized a picture of plain water is present around the face of the blades. The residue rate may rely upon droplet dimensions. The drinking water onto the blades leak into the border underneath the Impulse of this fog residue the effect of three facets, induce produced from the vapor haul, and thus the stress decline about the blade. [6,7] Water, on hitting the advantage of blades amass AR. Lots of the drops are over-large to become more stable. Drops of dimensions, five hundred to $1000 \mu \mathrm{m}$ will return under such a course. They do perhaps maybe not keep underneath the effect of mechanical drives and also internal linking that they float. These drops 2 wholly separate diameters -- just one using bigger diameter, so which likely comprise abundant with their bigger load of plain water and also possess the same rate as a lot of steam along with separate having all huge diameters a hundred - twohundred micro-meter or perchance lots of five-hundred micrometers with high comparative speed tactic the blades that are moving. The drops of diameter could move straight and reach on the blade, consequently erosion of blades. It is the conventional sections of compression rate and the part that is tangential is unheeded. [8,9]

\section{Warm Shower}

James Browing in 1983, who procured that the speed oxygen system. In HVOF that the feedstock covering powder is heated up to close over stage destroys by consuming gas flow generated from continuous beginning of energies including methane, gas, propylene or hydrogen. It's been represented with Cr plating procedure that was tricky demand the price tag is large that will be excessively of 5 times as appraised. Covering spared using vapor announcement system show land and that the wear advances. The implementation of the masking remains because of their depth. Covering process that is diverse will be being forced to deal with challenges increased from the market head-way and also the heaps set matters from the respect contest and substances controls as well as ordinary, wealth and safety requirements. Coatings created by dot seem like instead of a different as Cr plating [10]. 


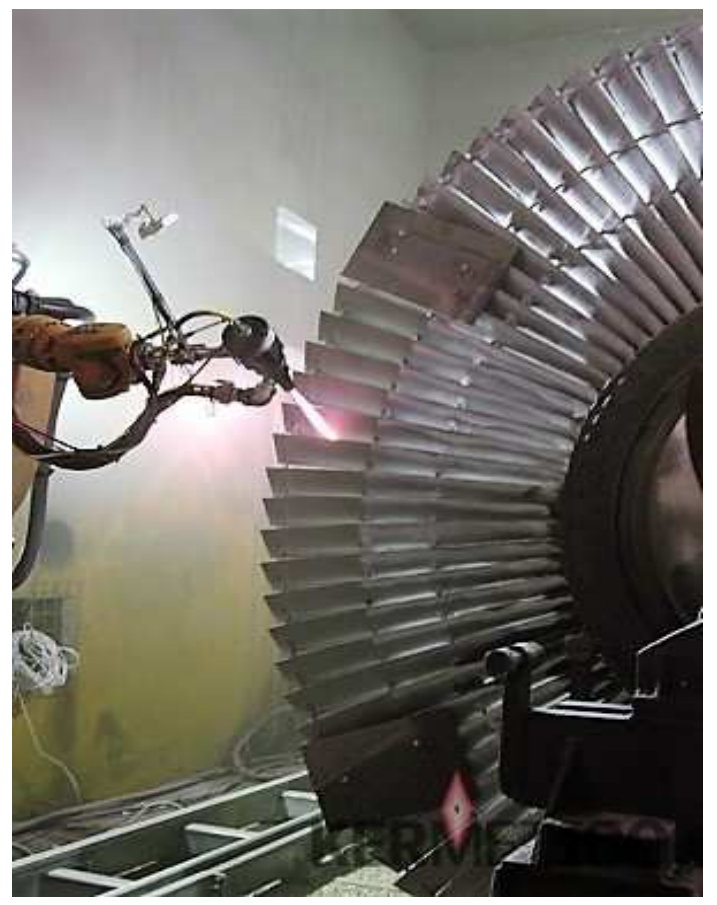

Figure 1: Warm Spray Coating [2]

\section{Explosion Gun}

Blast firearm can be really actually just a feasible, rapid technique covering development in hot technique. The blast that is predictable sprinkle Union Carbide manufactured in 1958 methods. There is then directly powder cloth planted into the rifle at a mixture of oxygen and acetylene. This combination has been burned off and accomplishes a rate. Imperativeness is given by this essentialness steam into the nourish inventory powder that reach seed. Because of fast of part because they truly have been somewhat less trek hot and because of accelerate creates that affects the contaminants. Of masking explanations, this kind gives security grade one of porosity along with covering and substrate powder. This estimation of HVOF approaches is more [8].

\section{WC-CO Based Coating}

Blends of tungsten carbide metal system have striking mechanical properties credits to the high hardness passed on by tungsten carbide WC and incredible quality advanced by metal system organize for instance $\mathrm{CO} \mathrm{CoCr}$ and $\mathrm{Ni}$. The guideline extent of WC-Co structure usually uses $86-88 \%$ WC and 6-13\% Co with or without an additional $1.5-8 \%$ Cr. Amid warm sprinkling a laminar or semi fluid particles influence on the substrate to shape a laminar covering made out of various layers called splats. One of the basic features of warm shower coatings is the small scale basic modification which occurs in the midst of powder getting ready and sprinkling such rot decarburization were discovered likely to widely change the wear lead of WC-M composites focused the association among structure and properties are distinctive warm sprinkled WC-Co covering and spectator at disintegration and scratched region assurance for HVOF covering concentrated and plasma showered and related this direct to the lower dimension of decay and little proportion of porosity gave in the midst of HVOF procedures. Which conceivably occur at the high temp. Related with warm shower. T. Sahraoui declared that covering which comprise of high centralization of tungsten monocarbides jewels in XRD examination attest in like manner the proximity of a greater dimension of WC[9]. 


\section{RESULTS}

The elevated oxygen fuel (HVOF) methodology was shown to appreciate covering broadly cut right down measurement of carbide dis-integration and period shift. Such as covering disperse of levels, institution porosity still left hot scatter covering's implementation depends upon. Everyone of this property so restrain the hardness of this covering, and it can be used for assessing wear test for a parameter. Various match means of masking spared making use of scope of treatment parameters to shop burst bathtub reported and covering that contrasts and respond to alloy foil, things believed, Co to form ternary carbides or blended W-C-M mixes, at which $\mathrm{M}$ is Co," CoCr, along with Tim and therefore on.

\section{CONCLUSIONS}

The shower heat, mass, and electricity commerce depict guaranteed statement frame for its announcement of have on covering that is risk-free miracles. These wonders are elements of this shower course of action parameters and also impression microstructure of the wear and the properties covering. HVOF have been associated with upgrade the organization's line of this telescope border. Perfect percentage of alloy disperse within compresses credibility essential to boost the cavitation's or dis-integration block of fragments. At that the depth will be pores in lower, that the dis-integration immunity is extended. Material home is not comparable to this associated with dis-integration from WC's amount quality covering that is especially successful is covering. Even the HVOF methodology is utilized to retail shop covering through and during cut dimensions of period shift and rust. Of masking, Even the implementation depends upon possessions border step, staying bodyweight, microstructure, so forth and porosity. The insurance policy coverage policies plan in usage of rest room has been regarded as even improved if cobalt is utilizing because meta proof.

\section{REFERENCES}

1. K. Asai, T. Kudo, and H. Yoda, "Experimental Validation of Fretting Fatigue Strength and Fretting Wear Rate at Contact Surface of Turbine-Blade-Shroud Cover,” J. Eng. Gas Turbines Power-Transactions ASME, vol. 136, no. 4, Apr. 2014.

2. S. Yan, D. Zhu, K. Zhuang, X. Zhang, and H. Ding, "Modeling and analysis of coated tool temperature variation in dry milling of Inconel 718 turbine blade considering flank wear effect," J. Mater. Process. Technol., vol. 214, no. 12, pp. 2985-3001, Dec. 2014.

3. J. R. Laguna-Camacho et al., "A study of the wear damage on gas turbine blades,” Eng. Fail. Anal., vol. 61, pp. 88-99, Mar. 2016.

4. J. Schlobohm et al., "Turbine blade wear and damage - An overview of advanced characterization techniques," Mater. Test., vol. 58, no. 5, pp. 389-394, May 2016.

5. Sharma, A., \& MA, M. (2016). Modeling and Finite Element Analysis of Vertical Axis Wind Turbine Rotor Configurations. International Journal of Mechanical and Production Engineering Research and Development (IJMPERD) ISSN (P), 22496890 .

6. G. Ilieva, "Mechanisms of Water Droplets Deposition on Turbine Blade Surfaces and Erosion Wear Effects," J. Appl. Fluid Mech., vol. 10, no. 2, pp. 551-567, 2017.

7. Ganesh, N., Kumar, M. U., Kumar, C. V., \& Kumar, B. S. (2014). Optimization of cutting parameters in turning of EN 8 steel using response surface method and genetic algorithm. International Journal of Mechanical Engineering and Robotics Research, 3(2), 75. 
8. J. Schlobohm et al., "Advanced characterization techniques for turbine blade wear and damage," in Proceedings of the 5th International Conference in Through-Life Engineering Services, 2017, vol. 59, pp. 83-88.

9. S. Luo, D. Zhu, L. Hua, D. Qian, and S. Yan, "Numerical analysis of die wear characteristics in hot forging of titanium alloy turbine blade," Int. J. Mech. Sci., vol. 123, pp. 260-270, Apr. 2017.

10. Profile Modification of Wind Turbine Blade for Improving Efficiency

11. D. A. Quintanar-Gago, P. F. Nelson, and A. Diaz-Sanchez, "Time And Spatial Modeling Of Wear Mechanisms In Nuclear Steam Turbine Blades Using Dynamic Bayesian Networks," in Proceedings of the ASME power conference, 2018, VOL 2, 2018.

12. K. Asai, S. Ishizawa, and N. Isobe, "Fretting Fatigue And Wear of TI-6Al-4v With HVOF Sprayed Stellite Coating On Contact Surfaces Of Shrouds And Stubs Of Turbine Blades," In Proceedings Of The ASME Turbo Expo: Turbomachinery Technical Conference And Exposition, 2018, Vol 7a, 2018, pp. 117-129.

13. M. Lavella and D. Botto, "Fretting wear of alloy steels at the blade tip of steam turbines," WEAR, vol. 426, no. A, pp. 735740, Apr. 2019. 
